\title{
Predicting mask-wearing behavior intention among international students during COVID-19 based on the theory of planned behavior
}

\author{
Yanjun Sun ${ }^{1}$, Banghui Qin ${ }^{1}$, Zhiqing $\mathrm{Hu}^{1}$, Huanan $\mathrm{Li}^{2}$, Xin $\mathrm{Li}^{3}$, Yuan $\mathrm{He}^{1}$, Huaxing Huang ${ }^{4}$ \\ ${ }^{1}$ School of Marxism, Nanjing Medical University, Nanjing, China; ${ }^{2}$ Department of Pharmacy Practice, Thomas J. Long School of Pharmacy, \\ University of the Pacific, Stockton, CA, USA; ${ }^{3}$ Department of Clinical Pharmacy, School of Pharmacy, Nanjing Medical University, Nanjing, China; \\ ${ }^{4}$ The First Clinical Medical College, Nanjing Medical University, Nanjing, China \\ Contributions: (I) Conception and design: Y He, H Huang; (II) Administrative support: Y He, H Huang; (III) Provision of study materials or patients: \\ Y Sun, B Qin; (IV) Collection and assembly of data: Y Sun, B Qin, X Li, Z Hu; (V) Data analysis and interpretation: Y Sun, B Qin, H Huang; (VI) \\ Manuscript writing: All authors; (VII) Final approval of manuscript: All authors. \\ Correspondence to: Yuan He. School of Marxism, Nanjing Medical University, 101 Longmian Avenue, Jiangning District, Nanjing 211166, China. \\ Email: heyuan@njmu.edu.cn; Huaxing Huang. The First Clinical Medical College, Nanjing Medical University, 101 Longmian Avenue, Jiangning \\ District, Nanjing 211166, China. Email: huanghuaxi@njmu.edu.cn.
}

\begin{abstract}
Background: The global outbreak of the coronavirus disease 2019 (COVID-19) has emerged as a major public health threat. This study aimed to analyze the influencing factors of international students' intention to wear a mask based on the theory of planned behavior (TPB). The findings are important because they provide pertinent information in designing and implementing COVID-19 prevention programs.
\end{abstract}

Methods: Self-designed questionnaires were distributed to 477 international students. Exploratory factor analysis (EFA) and confirmatory factor analysis (CFA) was conducted to identify and confirm the factor structure, and the structural equation model (SEM) was applied to determine the predictors of masks wearing.

Results: The final structural model was well reflected by fit indices. The research model of international students' intention to wear a mask for protection against COVID-19 was acceptable. All of the hypotheses were supported. Attitude and perceived behavioral control (PBC) were positively related to behavior intention (BI), respectively. Subjective norm (SN) also had a direct effect on attitude, PBC, and BI.

Conclusions: Referring to TPB was useful in identifying determinants of mask-wearing. The strongest predictor was SN, which indicated it was deserving of increased attention. These findings are significant to strengthen international students' awareness regarding self-protection and enhance the effectiveness of COVID-19 prevention programs.

Keywords: Coronavirus disease 2019 (COVID-19); international students; prevention behavior intention (prevention $\mathrm{BI}$ ); theory of planned behavior (TPB); structural equation modeling (SEM)

Submitted Nov 10, 2020. Accepted for publication Dec 30, 2020.

doi: 10.21037/apm-20-2242

View this article at: http://dx.doi.org/10.21037/apm-20-2242

\section{Introduction}

The coronavirus disease 2019 (COVID-19) swept through the world in 2020 and had a very detrimental impact on the global populations' health and development. The disease is spread through direct and indirect contact, not only through droplet transmission and person-to-person contact but also through contaminated objects and airborne transmission (1). Even asymptomatic infections increase the risk of further spreading the epidemic disease. Although some patients have been successfully treated, no specific vaccine has been found to date. Thus, it is an important topic of global concern and a major challenge in the field of public health to know how to deal with COVID-19, 
control the spread, and mitigate its impact. In the absence of drug prevention, non-pharmaceutical interventions play a particularly important role in reducing the transmission of COVID-19, including border restrictions, quarantine and isolation, distancing, and changes in population behavior (2).

Among them, wearing a mask is an important response behavior for individuals to deal with COVID-19. A mask is a useful tool that helps protect individuals from the spread of acute respiratory infections and the transmission of pandemic influenza (3). Experiences of tackling COVID-19 in China suggest that wearing masks is an effective response behavior. Scientific research has also shown that wearing a mask plays an important role in responding to the epidemic. Research has suggested that using any mask can reduce the spread of the virus, even though the protection capabilities vary greatly among different types (4). If adopted sufficiently early, even nonmedical or homemade masks can reduce the viral spread (5). Research in Germany has suggested that when mandated as compulsory, the use of face masks decreased the cumulative number of registered COVID-19 cases between 2.3\% and $13 \%$ over 10 days. Wearing masks helped considerably in reducing the spread of COVID-19 (6).

In China, regardless of whether one is sick or healthy, it is recommended to wear a mask. There are unified maskwearing policies across the universities of China. In order to effectively prevent and control the epidemic on campus, the Ministry of Education of the People's Republic of China issued the Guidelines on COVID-19 Prevention and Control in Higher Education Institutes (7). It required students to wear masks on public transportation, in the classroom, in an elevator, and so on. Besides, college students must conform to rigorous mask-wearing standards established by the Ministry of Education of the People's Republic of China (8). Despite some ambiguity, a consensus was reached in March 2020 that people with symptoms, and staff in health-care settings, should wear masks. However, compliance discrepancies were seen among the general public in community settings (9-13). The reasons are the paucity of resources and the lack of effective community protection (14). Despite the death caused by the H1N1 virus worldwide, wearing a mask was also still found to be regarded as a physical barrier to freedom and individualism in many countries (15). There have been reports of Chinese people who wore a mask being attacked by strangers due to cultural differences outside of China (16). In April 2020, the number of countries that required citizens to wear masks increased as a part of efforts against COVID-19; also, public health agencies in the U.S., Germany, France, and New Zealand have requested that masks be worn. Accordingly, the World Health Organization (WHO) has revised the previously issued guidelines that discouraged the use of masks in public places $(9,17)$, but the practice of not wearing masks had serious adverse effects in the nascence of COVID-19.

As mentioned above, wearing a mask is an important component of individual non-pharmaceutical interventions for COVID-19. However, in addition to cultural background, many factors are known to affect mask-wearing. Also, the reality of masks is not optimistic. Although advice on masks varies in different countries, masks' use will be more than usual when the local epidemic begins. The increase in the usage of masks worldwide will cause a shortage of masks, with prices soaring worldwide (18). Additionally, to an extent, government recommendations or compulsory orders may be deemed essential to help shape the perceptions of the masks' availability for the general population (5). Therefore, the usefulness, resources, prices, and government advice are factors that affect mask-wearing.

Wearing a mask, which is controversial due to cultural norms, is an effective and important non-pharmaceutical intervention of COVID-19 and is affected by multiple factors. Thus, it is important to know how to bolster enthusiasm for this non-pharmaceutical intervention against COVID-19. We must take the factors that influence wearing a mask into account when designing and implementing prevention programs of COVID-19.

However, a few studies have been conducted on several aspects of health protection by wearing masks in response to the epidemic. Based on a health belief model (HBM), a few studies have also been conducted on the behavior of adults or adolescents regarding wearing masks to prevent severe acute respiratory syndrome (SARS) in Hong Kong $(19,20)$. Many other theories are commonly used to study other health preventive behaviors in addition to HBM $(21,22)$, such as social cognitive theory (SCT) (23), the transtheoretical model of change (TTM) (24), the theory of reasoned action (TRA) (25) and the theory of planned behavior (TPB). Social factors are important in addressing cultural differences in wearing masks to prevent COVID-19. Thus, we must comprehensively take several more factors into account. In addition to taking the individual's internal factors into account, TPB places the individual in the external social background, and the characterization of the individual's social environment is also measured in the model (26). The present study was 


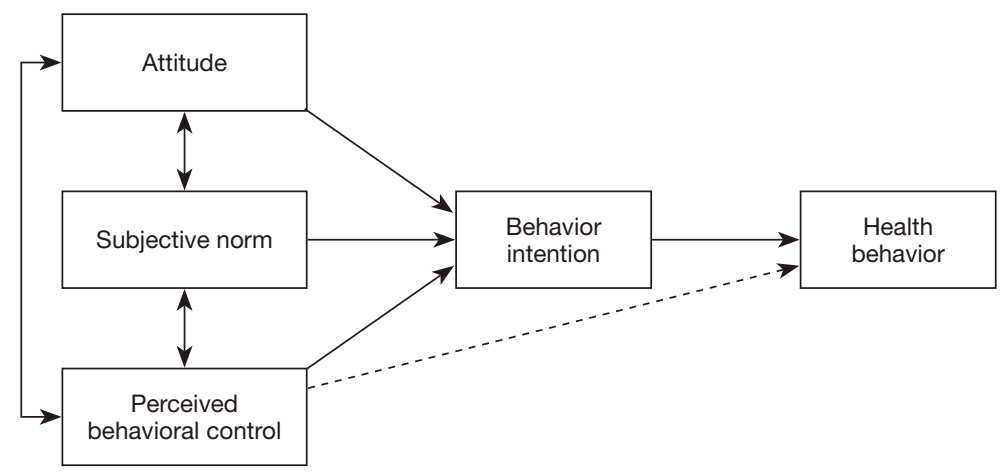

Figure 1 A framework of the TPB (29). TPB, theory of planned behavior.

conducted to explore adults' motivations to wear pollutionmasks to preserve health based on TPB (27).

TPB is a SCT that entails an analysis of the factors affecting behavior and predicting the intention to explain humans' decision-making process. The TPB model originated from TRA proposed by Fishbein and Ajzen. In 1985, Ajzen put forward TPB, integrating perceived behavioral control (PBC) into TRA (28). There are five elements to the TPB SCT, including attitude, subjective norm (SN), $\mathrm{PBC}$, behavior intention (BI), and behavior. The theory explains how attitude, SN, PBC act on BI, and then on the actual behavior. On the other hand, actual behavior is determined by BI, which, in turn, is determined by attitude, $\mathrm{SN}$, and PBC. Of these factors, three are independent and pairwise. Accurate PBC reflects the actual control conditions; thus, it can be used as an alternative measure of actual control conditions to directly predict the possibility of behavior occurrence (as illustrated in the dashed line in Figure 1) (30). The TPB is widely used in the field of health care and public health, including health prevention behaviors such as acquired immune deficiency syndrome (AIDS) prevention (31), cancer screening (32), diet for obesity (33), use of anti-pollution mask (27), smoking interventions (34), and others, as well as safety preserving behaviors such as seat belt (35-37) and helmet use (38,39). Additionally, the number of preventative health behavior studies continues to rise; for example, the domain of cervical cancer (40) and breast cancer screening (41). Previous studies have shown that TPB can effectively interpret health behavior, which is also a good model for predicting behavioral intention. The diagram of the structural model for health behavior is shown in Figure 1 (29).

Wearing a mask for protection against COVID-19 is a non-drug intervention for the preservation of health and safety. Based on the above analysis, coupled with the context of wearing masks in the time of COVID-19, TPB has been deemed more appropriate for exploring the intention to wear a mask to combat COVID-19. Against this backdrop, the present paper used TPB to study the intention to wear a mask in response to COVID-19.

International students are a pertinent group in the realm of preventing the spread of COVID-19. International students studying in China are an important component of Chinese universities. In recent years, the number of international students coming to China has increased from 11,500 in 1999 to 241,500 in 2017, which denotes an increase of nearly 21 times with an average annual growth rate of $18.43 \%$ (42). The data shows that international students are a growing sector of the local Chinese population. Peer mentoring plays an important role in personal health behavior (43). However, despite the spread of the epidemic, large parties of students have been accommodated at off-campus apartments in some countries against departmental mandates. Within these parties, the number of people in attendance exceeded the limit conveyed by the state admission. Additionally, the attendees were reportedly not wearing masks or adhering to physical distancing guidelines (44). Peer groups' behavior may be considered to impact the international students' enthusiasm for preventative measures, for example, the behavior or intention of wearing a mask. Therefore, it is necessary to strengthen the management of international students in the climate of COVID-19 upon students' return to campus. This contingent is also important in higher education abroad and, to some extent, role-models for the general population. Under the normalization of epidemic prevention and control, this significant group merits more attention on the issue of wearing masks. The 


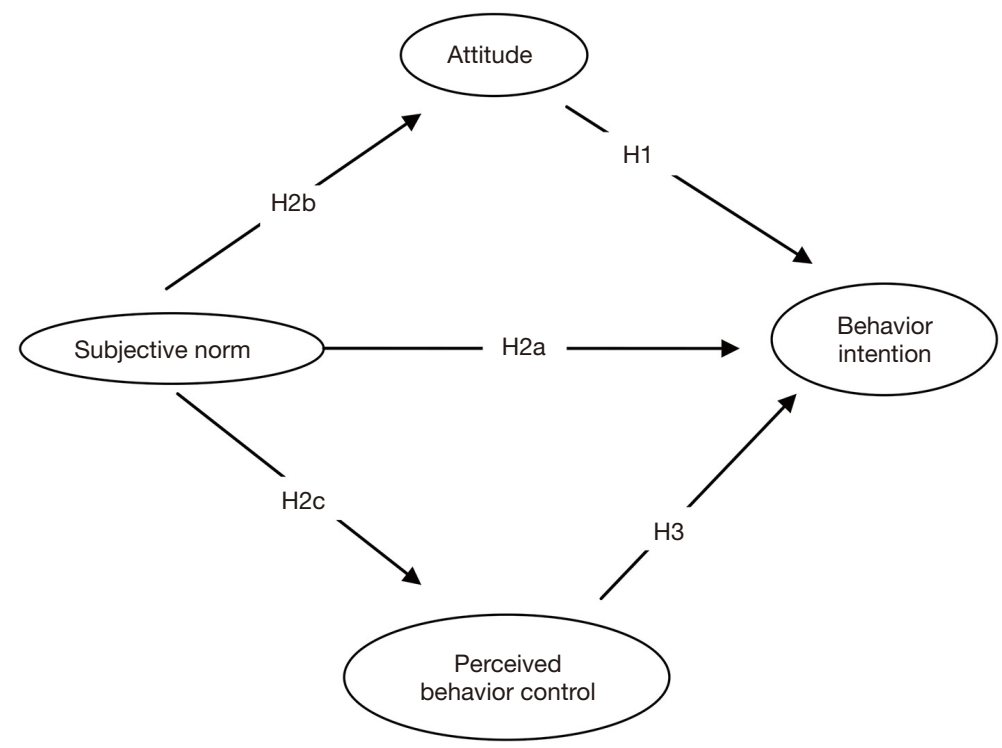

Figure 2 The research model of international students' intention to wear a mask for protection against COVID-19.

analysis is required regarding the mask-wearing intentions of international students and which factors appropriately encourage them to wear masks and strengthen awareness, education, or intervention on protection.

This study aimed to analyze the factors that influence international students' intention to wear a mask based on the TPB. Findings from this study could provide information relevant to designing and implementing COVID-19 prevention programs. We present the following article in accordance with the SURGE reporting checklist (available at http://dx.doi.org/10.21037/apm-20-2242).

\section{Methods}

\section{Research model and hypothesis development}

We assumed the research model and proposed the hypotheses by assimilating previous studies based on TPB (Figure 2).

Attitude refers to the degree to which one has a positive or negative appraisal of performing a certain behavior (30). This study's attitude referred to international students' appraisal of wearing a mask, including the necessity and other factors. According to TPB, attitude affects BI (30). Relevant research findings have suggested that attitude positively predicted the intention of health and safety preservation behaviors. Several studies on the use of seat belts have indicated that attitude was positively associated with the BI $(35,36)$. In the study of exploring motivations behind the use of pollution masks, the attitude was one of the positive factors used for the intention to wear a pollution-mask (27). Based on these previous findings, we hypothesized that international students would be more positively willing to wear a mask if they had a positive appraisal of wearing a mask against COVID-19.

Hypothesis $1(\mathrm{H} 1)$ : attitude is positively associated with the intention to wear a mask.

$\mathrm{SN}$ highlights the perceived social influence toward performing a given behavior. It refers to individuals' beliefs about the extent to which others would expect them to perform a behavior (30). The SN in this study is the object and group that influence the international students' intention to wear a mask to protect against COVID-19. According to TPB, SN affects BI (30). Relevant research findings showed that $\mathrm{SN}$ positively predicted BI. For example, in the study of smoking intention among Chinese youth for health interventions, for never-smokers, $\mathrm{SN}$ had the strongest relationship to intention (34). Besides, attitude and $\mathrm{SN}$ were also observed as positively related to intention to use a seat belt, not only for urban roads but also for rural roads (35). Thus, we assume that as perceived controllability increases, the intention to wear a mask will increase.

Hypothesis 2a (H2a): SN is positively associated with the intention to wear a mask.

According to TPB, $\mathrm{SN}$ is associated with attitude and $\mathrm{PBC}$ (30), and as such, if the SN varies, attitude and $\mathrm{PBC}$ 
will vary concordantly. In this way, SN may influence attitude and $\mathrm{PBC}$. Therefore, we assumed the following hypotheses:

Hypothesis 2b (H2b): SN affects attitude toward wearing a mask.

Hypothesis 2c (H2c): SN affects PBC of wearing a mask.

The $\mathrm{PBC}$ refers to individuals' discrimination in performing the behavior in question (30). In this study, the $\mathrm{PBC}$ is the international students' discernment to wear a mask against COVID-19, including material, price, quality, etc. According to TPB, PBC affects BI (30). The study of health behavior demonstrated that $\mathrm{PBC}$ was the strongest positive predictor of cervical cancer screening intentions (45). Besides, $\mathrm{PBC}$ was the strongest positive determinant of smoking behavior among Iranian medical students (46). It also had the highest positive correlation with the intention of seat belt use (37). Therefore, we hypothesized that $\mathrm{PBC}$ is a positive predictor of wearing a mask against COVID-19.

Hypothesis 3 (H3): $\mathrm{PBC}$ is positively associated with the intention to wear a mask.

\section{Instruments and measures}

Based on an analysis of the current situation of wearing masks, a self-administered questionnaire was designed against the backdrop of COVID-19 and the existing research, combined with ТРВ. To develop these items, we reviewed all of the available previous research papers $(27,47)$. In this study, some measures were adapted from previous research. Additionally, the usefulness, resource, price, and other elements of masks in the setting of COVID-19 (as shown in the introduction, paragraph 1-5) were fully taken into account before the questionnaire was created.

Pretest and reasonable adjustments were conducted before the formation of the formal questionnaire. The formal questionnaire consisted of two parts: the attitude and behavior of wearing a mask and the participants' demographic characteristics (28 questions in total). There were 20 questions in Part I, including attitude (3 questions), SN (9 questions), PBC (4 questions), and intention to wear a mask (3 questions). And the 9 questions in Part II related to the demographic characteristics of participants. The items in Part I were scored on a 5-point Likert scale with possible answers of strongly disagree, disagree, neutral, agree, and strongly agree or never, seldom, sometimes, often, and always, ranging from $1-5$ points. In particular, the scores of three items toward attitude, which were reverse scoring, were ranged from 5-1 points.

We measured international students' intention to wear a mask in different regions (their own countries or in China) and in different locations (subway, theater, elevator, park, library, classroom, square, business, or other places where crowds gather).

\section{Participants and data collection}

This was a cross-sectional study to test the hypotheses. The questionnaire was used to investigate international students studying in China. Potential participants were recruited by convenience sampling in some universities in Nanjing. We distributed the questionnaire through a professional online questionnaire survey platform, with both evaluation and voting conducted in mainland China. This method was chosen due to its being convenient, quick, and easy to collect data. The WeChat Group released contact information. Intentional students were incentivized to return the questionnaires by the opportunity to enter themselves into a random prize draw to win $0-1 \$$. We reminded participants to fill out the questionnaire every 3 days between 14 May and 20 May 2020. The investigation's anonymous nature was explained as follows before answering the questions: data collected will be kept completely confidential and only be used within this study. Participants were reminded to fill out the questionnaire voluntarily and answer it truthfully.

\section{Statistical analysis}

Data were recorded using Microsoft Excel. Descriptive statistics including frequencies and proportion of each variable of demographics, such as gender, age, study major, grade, area number of family members, and family income (RMB per month), among others, were calculated using SPSS version 22.0 (IBM, Armonk, NY, USA). The hypothesis model was analyzed by the structural equation modeling (SEM) using Amos version 24.0 (IBM SPSS Amos, Armonk, NY, USA). Before testing the hypothesis model, we performed a factor analysis to identify and confirm the questionnaire's constructs. Exploratory factor analysis (EFA) was conducted by SPSS version 22.0, with the index of Kaiser-Meyer-Olkin (KMO) and Bartlett's test of sphericity. Principal component analysis (PCA) and varimax rotation were used to obtain the factor structure matrix. Cronbach's $\alpha \geq 0.600$ indicated sufficient internal consistency (48). Confirmatory factor analysis (CFA) was performed by Amos version 24.0 with the fit index 
including chi-square value of minimum sample/degree of freedom (CMID/DF), root mean square residual (RMR), standardized RMR (SRMR), root mean square error of approximation (RMSER), goodness of fit index (GFI), normed fit index (NFI), comparative fit index (CFI), Tucker-Lewis index (TLI), and so on. Composite reliability (CR), convergent validity and discriminant validity were also assessed by Cronbach's $\alpha$, average variance extracted (AVE), the AVE square root, and the correlations among variables.

Regarding the sample size, according to the Jiangsu Provincial Bureau of Statistics, the region was estimated to have 50,000 international students in 2020 (49). We calculated the sample size using Raosoft (www.raosoft.cpm/ samplesize.html) (50), which showed that the population size was 50,000 . Per procedure, the margin of error was $5 \%$, the confidence level was $95 \%$, the response distribution was $50 \%$, and the recommended sample size was 382 . If all the items were filled out, the questionnaire was regarded as completed. If one or more items were missing, the questionnaire was regarded as partially completed. In the case of missing data, we replaced the missing data with the respondents' mean in the same unit (51). This study's response rate was the ratio of the valid response size to the actual sample size.

\section{Ethics approval}

Ethical admission of this study was passed by the Ethics Committee of Nanjing Medical University [grant number:(2020)569]. Oral informed consent was provided by all international students who participated in the survey. The study was conducted in accordance with the Declaration of Helsinki (as revised in 2013).

\section{Results}

In the web-based survey, of the 550 questionnaires distributed, 492 were returned. Among the 550 questionnaires, 477 were usable for a response rate of $86.7 \%$. According to the item "which country do you currently live in", 87 participants still were in China, and 390 had returned home (the country they were currently living in).

\section{Demographics and characteristics}

According to the report of international education in
China, $59.95 \%$ of the international students in mainland China came from Asia, followed by Africa (16.57\%), Europe (14.96\%), the Americas (7.26\%), and Oceania (1.27\%) (52). The Asian students were mainly from Korea, Thailand, Pakistan, India, Laos, Kazakhstan, Vietnam, Bangladesh, Malaysia, etc. (52). The final database of this study comprised a total of 477 records. The participating international students came from 52 countries across 6 continents, namely Asia, Africa, Europe, North America, South America, and Oceania, and at the time of interview were residing in 37 countries across the globe, which covered the top 13 countries of the international students' nationality or residence (52). The sample framework was generally consistent with the report of international education in China in 2018.

Demographics and relevant characteristics of participants are shown in Table 1. The ratio of men to women was almost equal to $1: 1$. The minimum age was 17 years old, the maximum age was 45 , and the percentage of 21-25-yearold students was almost $47.8 \%$. The participants were primarily comprised of medical students $(86.4 \%)$. The grade was divided into three stages: undergraduate, master, and doctor, among which the number of undergraduates was the highest $(77.1 \%)$. The majority lived in urban areas They were predominantly with a family of 4 (36.3\%). The representativeness of the sample was reflected in social demographic information.

\section{Factor analysis}

The data of 477 samples were randomly divided into two parts using SPSS V.22.0. The EFA was conducted on 1 part of the data ( $\mathrm{n}=238)$, and the other part ( $\mathrm{n}=239$ samples) was used for the CFA to confirm the result of the EFA. The reliability and validity of this self-designed questionnaire were also analyzed.

\section{EFA}

The single sample $t$-test was conducted by the critical ratio (C.R.) between the top-ranked $27 \%$ of the other 16 items scores, and the lowest-ranked $27 \%$. The t-value of each item were all above three points and significant $(\mathrm{P}<0.001)$. Pearson's correlation coefficient was also significant $(\mathrm{P}<0.01)$. The value of $\mathrm{KMO}$ was 0.867 , and Bartlett's test of sphericity was significant $\left(\chi^{2}=2,080.587\right.$, $\mathrm{P}<0.001)$, which estimated the suitability of EFA (53). The results of EFA on the first part of the samples $(n=238)$ are shown in Table 2. A total of four factors were obtained 
Table 1 Demographics and relevant characteristics of participants $(\mathrm{n}=477)$

\begin{tabular}{|c|c|c|}
\hline Variables & Values & N (\%) \\
\hline \multirow[t]{2}{*}{ Gender } & Female & 265 (55.6) \\
\hline & Male & $212(44.4)$ \\
\hline \multirow[t]{5}{*}{ Age } & $\leq 20$ & $123(25.8)$ \\
\hline & $21-25$ & $228(47.8)$ \\
\hline & $26-30$ & 60 (12.6) \\
\hline & $31-35$ & 48 (10.1) \\
\hline & $\geq 36$ & $18(3.8)$ \\
\hline \multirow[t]{2}{*}{ Major } & Medical science & $412(86.4)$ \\
\hline & Others & 65 (13.6) \\
\hline \multirow[t]{3}{*}{ Grade } & Undergraduate & 368 (77.1) \\
\hline & Master & $61(12.8)$ \\
\hline & Doctor & 48 (10.1) \\
\hline \multirow[t]{2}{*}{ Live in } & Urban area & 366 (76.7) \\
\hline & Rural area & $111(23.3)$ \\
\hline \multirow{6}{*}{$\begin{array}{l}\text { Number of family } \\
\text { members }\end{array}$} & Only myself & $36(7.5)$ \\
\hline & 2 & $37(7.8)$ \\
\hline & 3 & $69(14.5)$ \\
\hline & 4 & $173(36.3)$ \\
\hline & 5 & $98(20.5)$ \\
\hline & $\geq 5$ & $64(13.4)$ \\
\hline \multirow{7}{*}{$\begin{array}{l}\text { Family income } \\
\text { (RMB per month) }\end{array}$} & $\leq 3,000$ & $94(19.7)$ \\
\hline & $3,000-6,000$ & $115(24.1)$ \\
\hline & $6,000-9,000$ & $40(8.4)$ \\
\hline & $9,000-12,000$ & $58(12.2)$ \\
\hline & $12,000-15,000$ & $18(3.8)$ \\
\hline & $15,000-18,000$ & $5(1.0)$ \\
\hline & $\geq 18,000$ & $147(30.8)$ \\
\hline Total & - & $477(100.0)$ \\
\hline
\end{tabular}

according to the eigenvalue $\geq 1$, and the total variance explained was $69.64 \%$. We removed item 20 due to its factor loading being only 0.496 , far below other values. All factor loadings of the other 15 items were above 0.600 . All factors' Cronbach's $\alpha$ was above 0.600 , which met the minimum criterion and indicated acceptable internal consistency (48).
Table 2 The results of EFA $(\mathrm{n}=238)$

\begin{tabular}{|c|c|c|c|}
\hline Factors/items & $\begin{array}{c}\text { Factor } \\
\text { loadings }\end{array}$ & Eigenvalue & $\begin{array}{c}\text { Cronbach's } \\
\alpha\end{array}$ \\
\hline Attitude & & 1.237 & 0.643 \\
\hline Item1 (Attitude1) & 0.731 & & \\
\hline Item2 (Attitude2) & 0.832 & & \\
\hline Item3 (Attitude3) & 0.742 & & \\
\hline SN & & 6.360 & 0.929 \\
\hline Item4 (SN1) & 0.819 & & \\
\hline Item5 (SN2) & 0.866 & & \\
\hline Item6 (SN3) & 0.829 & & \\
\hline Item7 (SN4) & 0.836 & & \\
\hline Item8 (SN5) & 0.829 & & \\
\hline Item10 (SN6) & 0.781 & & \\
\hline PBC & & 1.536 & 0.731 \\
\hline Item13 (PBC1) & 0.845 & & \\
\hline Item14 (PBC2) & 0.789 & & \\
\hline Item15 (PBC3) & 0.731 & & \\
\hline $\mathrm{BI}$ & & 2.009 & 0.824 \\
\hline Item16 (Bl1) & 0.641 & & \\
\hline Item18 (BI2) & 0.835 & & \\
\hline Item19 (BI3) & 0.838 & & \\
\hline
\end{tabular}

EFA, exploratory factor analysis; SN, subjective norm; PBC, perceived behavioral control; $\mathrm{BI}$, behavior intention.

\section{CFA}

The CFA results on the remaining part of the samples $(\mathrm{n}=239)$ are shown in Figure 3 and Table 3 . The standardized regression weights of all items were above 0.05 . The values of the C.R. were all significant $(\mathrm{P}<0.001)$. The standard error of estimate values was below 2.5, which indicated the model was suitable for the sample. Then, CMID/ $\mathrm{DF}=2.063<5$ (54) and fit indices $[\mathrm{RMR}=0.039<0.05$ (55), SRMR $=0.058<0.08(56)$, RMSER $=0.067<0.08$ (57), GFI $=0.914>0.900(58)$, NFI $=0.906>0.900$ (59), CFI $=0.948>0.900(56)$, and TLI $=0.935>0.900(56)]$ showed the structure was acceptable for our purposes.

As shown in Table 4, the questionnaire's reliability and validity included Cronbach's $\alpha, \mathrm{CR}, \mathrm{AVE}$, and correlations among variables. Cronbach's $\alpha \geq 0.700$ indicated sufficient internal consistency or reliability and that CR was adequate. Meanwhile, the value of the AVE showed that 


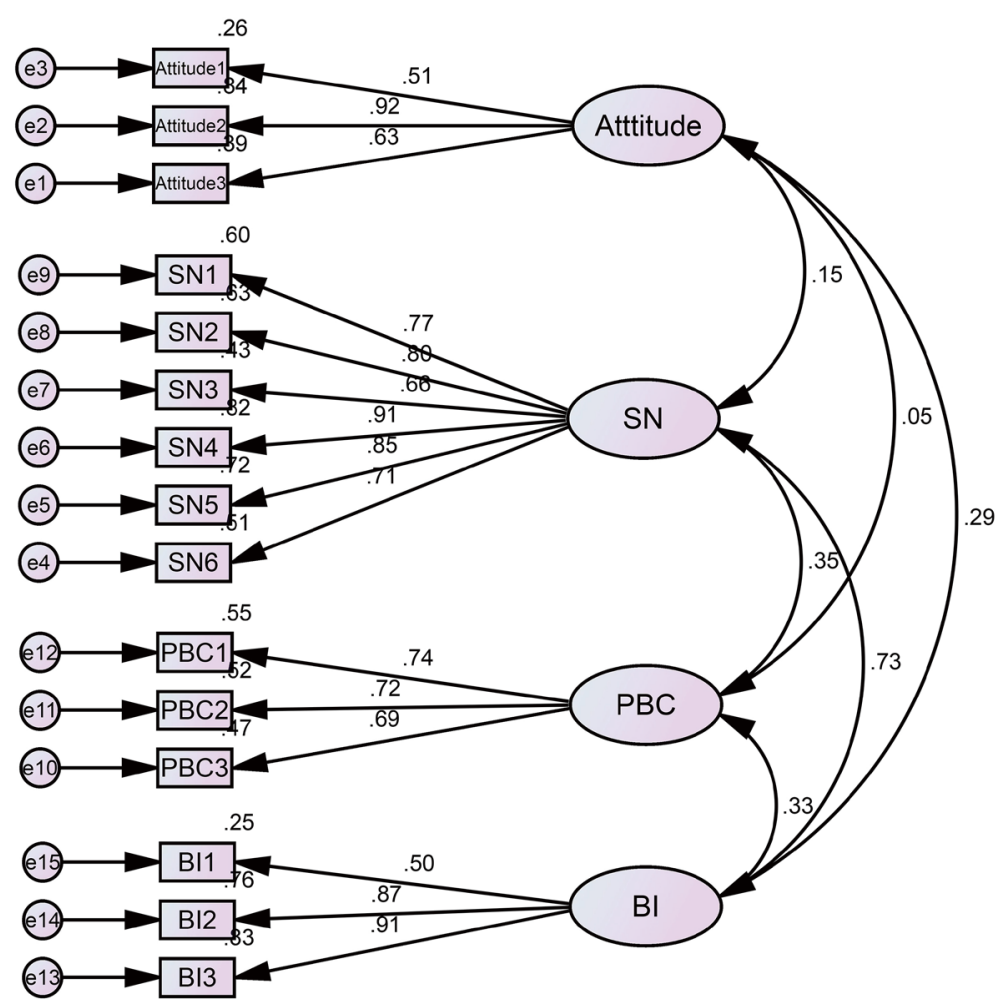

Figure 3 The model of CFA on the Attitude, SN, PBC and BI ( $\mathrm{n}=239)$. Attitude1-Attitude 3 denote the three items used to measure the respondents' attitudes; SN1-SN6, the six items used to measure the respondents' SN; PBC1-PBC3, the three items used to measure the respondents' $\mathrm{PBC}$; $\mathrm{BI} 1-\mathrm{BI} 3$, the three items used to measure the respondents' behavior intention. BI, behavior intention; $\mathrm{PBC}$, perceived behavioral control; $\mathrm{SN}$, subjective norm.

the convergent validity was acceptable. The discriminant validity of the questionnaire was assessed. It was evident that the AVE square root of each construct was higher than the absolute value of their correlation (60); the crossloadings showed that all items loaded on their respective constructs were higher than on the other constructs, and the cross-loadings differences were above the threshold of $0.10(61)$.

\section{Evaluation of structural model}

The CMID/DF (3.527) and fit indices RMR (0.036), SRMR (0.068), RMSER (0.073), GFI (0.904), NFI (0.881), CFI (0.911), and TLI (0.935) all indicated the model was acceptable.

The model's measurement results are shown in Table 5 $(\mathrm{n}=477)$, Figure $4(\mathrm{n}=477)$, and Table $6(\mathrm{n}=477)$. The C.R. values were all above 3.25 , which indicated the estimates were significant $(\mathrm{P}<0.001)$. As shown in Figure $4(\mathrm{n}=477)$, about $48 \%$ of the variance in the intention to wear a mask was explained: attitude was $4 \%$, and $\mathrm{PBC}$ was $12 \%$, and the path diagram showed how attitude, SN, and PBC predicted the BI to wear a mask.

Figure $4(\mathrm{n}=477)$ and Table $6(\mathrm{n}=477)$ show hypothesis testing results based on the model. Attitude and PBC were, respectively, directly and positively related to BI. The SN also had a direct effect on attitude, PBC, and BI. Besides, SN also indirectly promoted the BI through attitude and PBC. The effects of living area, countries where international students were living, and grade were controlled. The country was regarded as a dummy variable set to a value of 1 if the international student currently lived in China, and 0 otherwise, in the SEM. The same code was applied to the grades and living area. The standardized regression weights were $0.033(\mathrm{P}>0.05), 0.010(\mathrm{P}>0.05)$, and $0.013(\mathrm{P}>0.05)$, respectively, which indicated they were not significantly related to the BI to wear a mask. Thus, this hypothesis model was strongly confirmed, and all 
Table 3 The standardized regression weights of the model $(\mathrm{n}=239)$

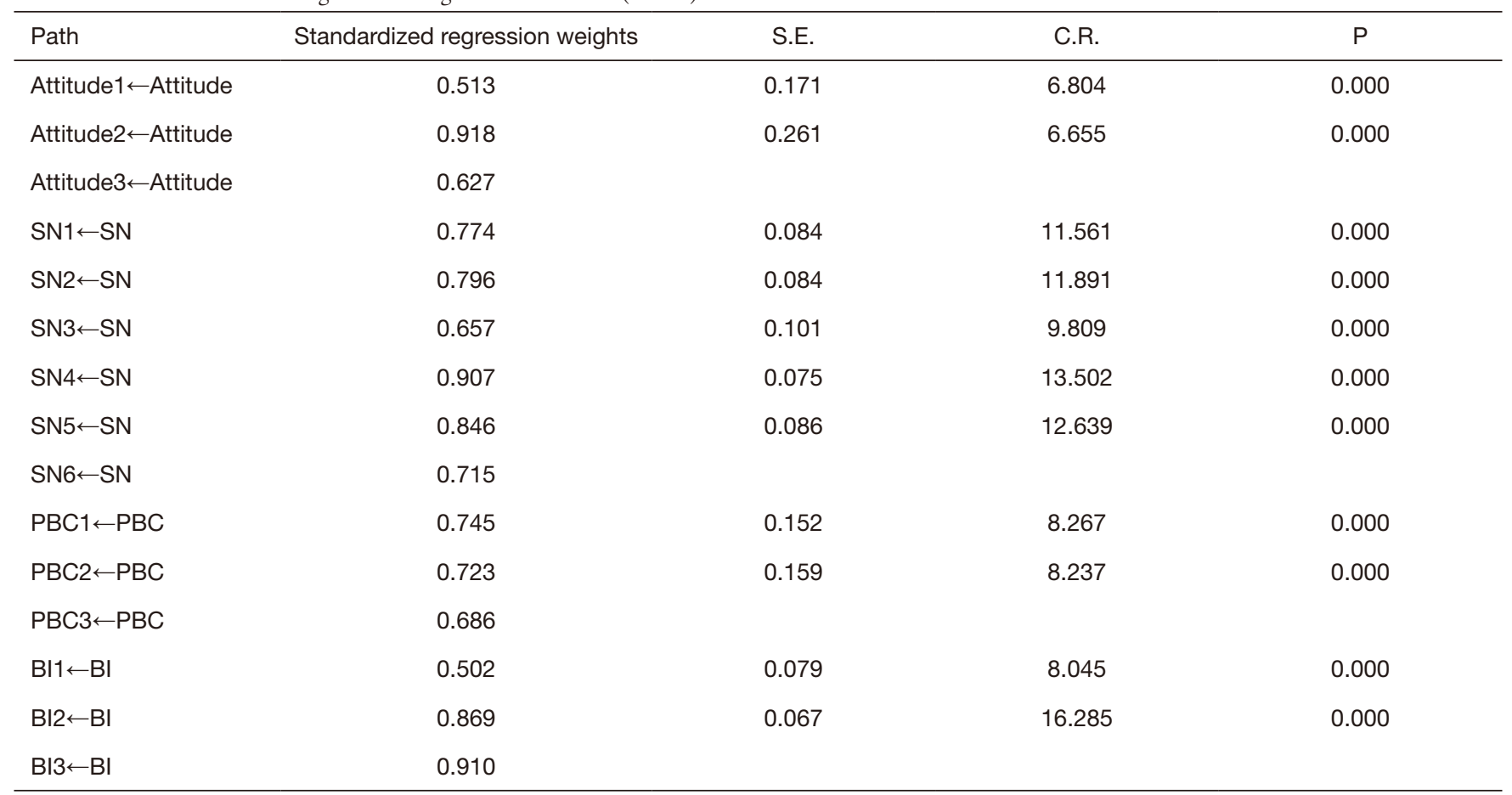

Attitude1-Attitude3 denote the three items used to measure the respondents' attitudes; SN1-SN6, the six items used to measure the respondents' SN; PBC1-PBC3, the three items used to measure the respondents' $\mathrm{PBC}$; BI1-BI3, the three items used to measure the respondents' BI. C.R., critical ratio; SN, subjective norm; PBC, perceived behavioral control; BI, behavior intention.

Table 4 Correlations among variables $(\mathrm{n}=239)$

\begin{tabular}{|c|c|c|c|c|c|c|c|}
\hline Factors & $\mathrm{R}$ & $\mathrm{CR}$ & AVE & $\mathrm{BI}$ & PBC & SN & Attitude \\
\hline PBC & 0.757 & 0.762 & 0.516 & 0.327 & 0.718 & & \\
\hline SN & 0.901 & 0.906 & 0.619 & 0.725 & 0.348 & 0.787 & \\
\hline Attitude & 0.702 & 0.738 & 0.500 & 0.294 & 0.053 & 0.150 & 0.707 \\
\hline
\end{tabular}

The square roots of the AVE are shown on the diagonal and italicized elements, below which are the correlations between the construct's values. BI, behavior intention; PBC, perceived behavioral control; SN, subjective norm; R, Cronbach's $\alpha$; CR, composite reliability; AVE, average variance extracted.

hypotheses were supported.

\section{Discussion}

According to the current study, (I) $7.5 \%$ of the 477 participants strongly disagreed, disagreed, or neither agreed nor disagreed on the view: "Even if all of the people around me do not wear a mask, I would like to wear it"; (II) $2.7 \%$ of the respondents had the same attitude towards the view: "If I have to go out, I plan to wear a mask"; (III) $1.2 \%$ of the respondents strongly disagreed or disagreed with the view that: "If I have to go out, I will wear a mask". These numbers indicated a low willingness to wear masks among some international students despite the widely established fact that the COVID-19 seriously affects people's life and health. This inference highlights the significance of exploring the factors that influence the BI to wear masks to improve self-protection awareness and strengthen the management of international students.

This study examined how various psychosocial factors 
Table 5 The standardized regression weights of the model $(\mathrm{n}=477)$

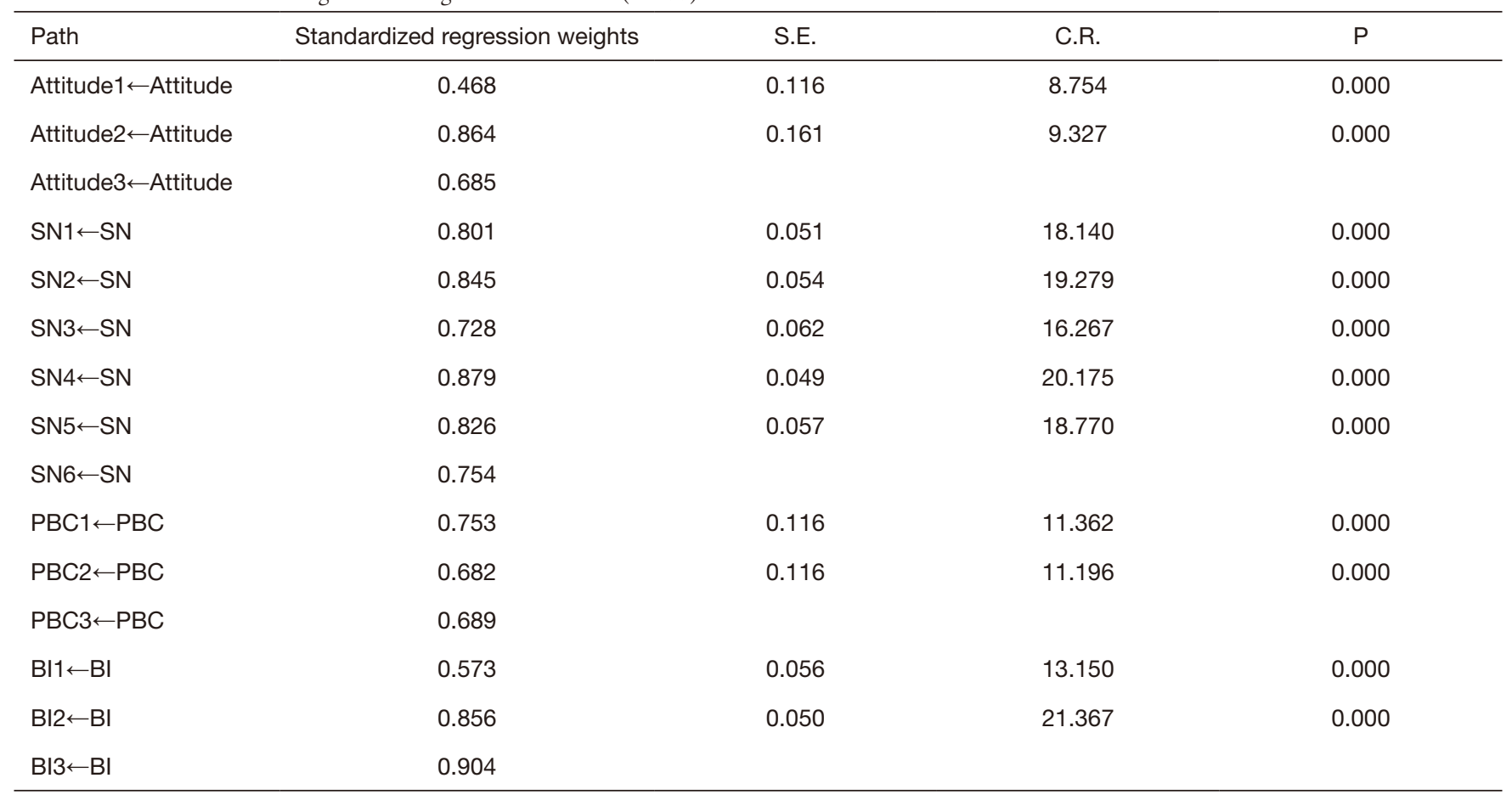

Attitude1-Attitude3 denote the three items used to measure the respondents' attitudes; SN1-SN6, the six items used to measure the respondents' SN; PBC1-PBC3, the three items used to measure the respondents' $\mathrm{PBC}$; $\mathrm{BI} 1-\mathrm{BI} 3$, the three items used to measure the respondents' BI. C.R., critical ratio; SN, subjective norm; PBC, perceived behavioral control; BI, behavior intention.

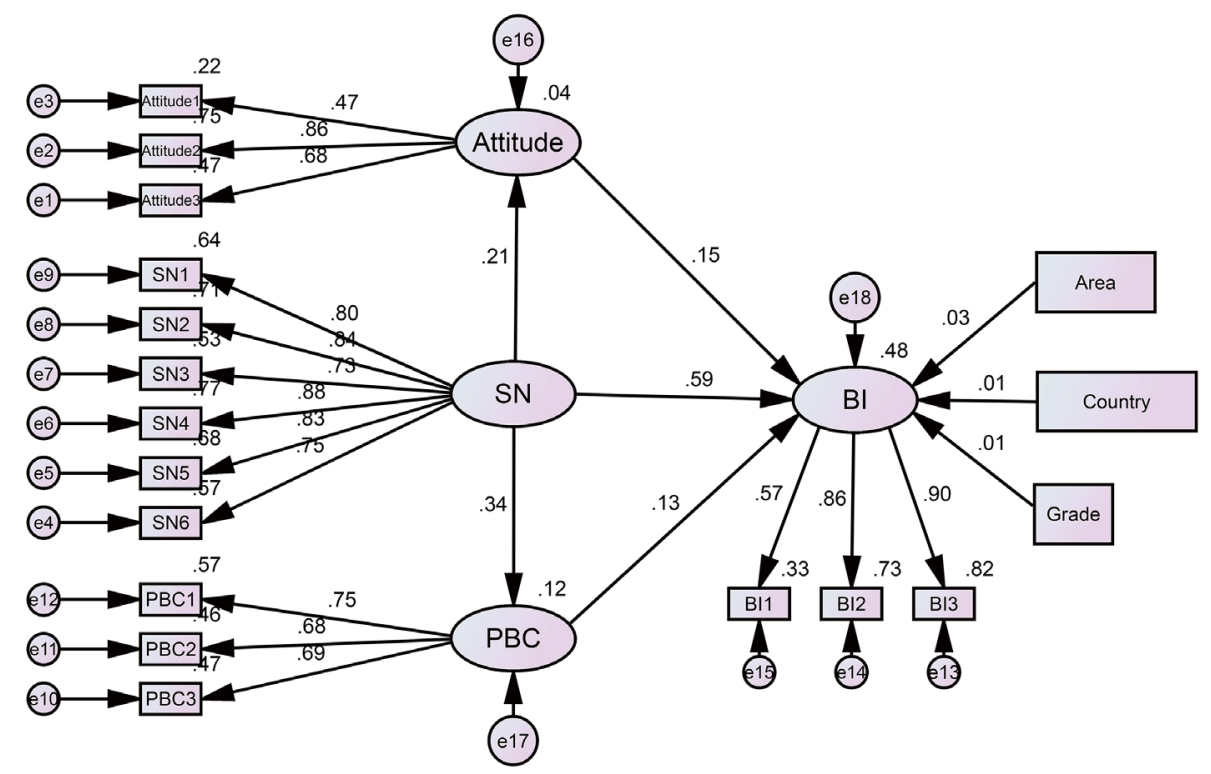

Figure 4 Path diagram for research model (n=477). Attitude1-Attitude3 denote the three items used to measure the respondents' attitudes; SN1-SN6, the six items used to measure the respondents' SN; PBC1-PBC3, the three items used to measure the respondents' PBC; BI1$\mathrm{BI} 3$, the three items used to measure the respondents' BI. Area means urban or rural area. Grade included undergraduate and postgraduate. Country means where the international students currently live. The grade, area, and country were all used as control variables. BI, behavior intention; PBC, perceived behavioral control; SN, subjective norm. 
Table 6 The path coefficients of the BI to wear a mask ( $n=477)$

\begin{tabular}{lcccc}
\hline Causal variables & Outcome variable & Standardized total effect & Standardized direct effect & Standardized indirect effect \\
\hline Attitude & $\mathrm{BI}$ & 0.148 & 0.148 & 0.000 \\
SN & $\mathrm{BI}$ & 0.664 & 0.588 & 0.075 \\
& Attitude & 0.210 & 0.210 & 0.000 \\
& PBC & 0.340 & 0.340 & 0.000 \\
PBC & $\mathrm{BI}$ & 0.131 & 0.131 & 0.000 \\
\hline
\end{tabular}

$\mathrm{BI}$, behavior intention; $\mathrm{PBC}$, perceived behavioral control; SN, subjective norm.

were associated with the intention of COVID-19-specific behavior (wearing a mask) among international students studying in Nanjing, China. Similar to extant studies (27,28,30-38), it demonstrated that the TPB model could be well suited to understand better international students' intention to wear masks. This study is unique in that, and unlike previous studies, it took into account the intention of wearing a mask, including influencing social factors. As hypotheses, international students' attitude, $\mathrm{PBC}$, and SN were significant predictors of wearing masks. Additionally, $\mathrm{SN}$ was significantly related to attitude and $\mathrm{PBC}$, respectively. The results were consistent with the predicted relationships among the key TPB variables (attitude, $\mathrm{PBC}$, $\mathrm{SN}$, and intention).

The $\mathrm{SN}$ was the strongest determinant of the intention to wear a mask, consistent with previous studies' findings. For example, $\mathrm{Xu}$ et al. suggested that $\mathrm{SN}$ functioned as the strongest factor in predicting intention to participate (62). Moreover, some studies showed that environmental cues, such as government and family, also served as significant predictors of mask-wearing activities during the SARS outbreak (19). The study findings also favored other healthpreserving measures among the youngest cohorts (20) during quarantine periods (63). The $\mathrm{SN}$ is also related to attitude and $\mathrm{PBC}$; that is, $\mathrm{SN}$ is a necessary determinant that must be considered when designing and implementing COVID-19 prevention programs. These results indicated that multiple stakeholders should encourage international students to wear masks, including the local government, schools, public opinion, family, friends, and teachers. Therefore, more attention needs to be paid to these resources. Before international students return, the Chinese government and universities could send some advertising materials to promote the importance and usefulness of mask-wearing to their parents and teachers by email or other online tools. Due to the SN's key role in the model, parents and teachers could play a significant role in this supervision. Citizens in some countries have been forced to wear a mask or incur a fine (64). Accordingly, after overseas students return to China, the international offices of universities should develop some appropriate management measures to motivate students to wear masks to minimize the spread of COVID-19. For example, the international office could mandate to wear a mask whenever they are in or out of the university.

The attitude was positively related to the intention to wear a mask for international students studying in China, which was consistent with previous studies' findings. The study of Şimşekoğlu (35) and Tavafian (36) et al. suggested that attitude had a positive effect on intention. Specifically, Hansstein (27) suggested attitude was positively related to the intention of wearing an anti-pollution mask. This finding indicated that it is possible to strengthen BI by improving attitudes towards wearing a mask. Firstly, the Chinese government and universities may publicly distribute brochures with information about COVID-19, facilitating the international students' adherence to the infection prevention guidelines. Besides, university officials should strengthen education on the preventive role of maskwearing to help dispel the international student's prejudices and enhance their awareness of wearing masks.

The $\mathrm{PBC}$ had a positive effect on the intention to wear a mask. These results have also been validated in previous studies, including Roncancio (45), Karimy (46), and Ali (37) et al. However, the results of research exploring motivations underpinning pollution-mask use have suggested that $\mathrm{PBC}$ was not significantly associated with the intention (27). The reason for this discrepancy could be that material resources, price, and quality have a stronger effect on wearing a mask during an epidemic than under normal circumstances. Generally speaking, the price may be reduced by increasing supply. Therefore, the high price of masks caused by the 
supply shortage could be adjusted by increasing production. The Chinese government and universities could regulate prices and improve product quality, which should eventually facilitate buying masks. Besides, to improve enthusiasm for wearing masks, the Chinese government and universities may develop some new policies. For instance, university officers could regularly distribute masks to international students or provide a certain amount of masks where necessary, reducing the perceived difficulty and increasing the accessibility of wearing masks.

The worldwide spread of COVID-19 requires significant attention. The volume of international students coming to China has been steadily rising. The international student participants in this study were sampled from all over the world, and they were representative of the international student groups across China. Hence, this study's results can be generalized to the management of all international students studying in China, not just within Nanjing. As a foreign group, the results of international students' research may be used as a reference for the health management of students in universities abroad.

This study had some limitations. First, this was a crosssectional study, which failed to consider the influential longitudinal factors of the intention to wear masks. To mitigate this shortcoming, the longitudinal contrast of mask-wearing can be added in future studies, and the predicting factors can be found from behavioral changes (before and after). Second, the study did not prove the relationship between knowledge of COVID-19 and BI. A previous study had shown that knowledge promoted healthpreserving measures (65). This is an area that would benefit from future research.

\section{Conclusions}

According to the current study, when COVID-19 emerged as a major public health threat, there was a low willingness among some international students to wear masks. In this study, we examined the influencing factors of the intention to wear a mask among international students in Nanjing, China-based on TPB. Despite a few limitations, the findings of this study have significant implications for the health promotion of international students and the prevention of COVID-19 transmission. The SN was revealed as a powerful motivating factor in international students' intention to prevent COVID-19 by wearing a mask, followed by attitude and PBC. Thus, the government, media publications, international offices, teachers, and peers should give full play to improve international students' attitude and encourage them to wear a mask. The attitude and $\mathrm{PBC}$ (shortages, supplies, price, quality, and so on) are also key factors that must be considered.

\section{Acknowledgments}

The authors would like to express their appreciation for all the research assistants in data collection. Special thanks to the anonymous reviewers and the editors for their useful comments.

Funding: The study was supported by the National Natural Science Foundation of China (grant No. 71804074). The funders had no role in study design, data collection and analysis, decision to publish, or preparation of the manuscript.

\section{Footnote}

Reporting Checklist: The authors have completed the SURGE reporting checklist. Available at http://dx.doi. org/10.21037/apm-20-2242

Data Sharing Statement: Available at http://dx.doi. org/10.21037/apm-20-2242

Peer Review File: Available at http://dx.doi.org/10.21037/ apm-20-2242

Conflicts of Interest: All authors have completed the ICMJE uniform disclosure form (available at http://dx.doi. org/10.21037/apm-20-2242). The authors have no conflicts of interest to declare.

Ethical Statement: The authors are accountable for all aspects of the work in ensuring that questions related to the accuracy or integrity of any part of the work are appropriately investigated and resolved. Ethical admission of this study was passed by the Ethics Committee of Nanjing Medical University [grant number: (2020) 569]. Oral informed consent was provided by all the international students who participated in the survey.

Open Access Statement: This is an Open Access article distributed in accordance with the Creative Commons Attribution-NonCommercial-NoDerivs 4.0 International License (CC BY-NC-ND 4.0), which permits the noncommercial replication and distribution of the article with 
the strict proviso that no changes or edits are made and the original work is properly cited (including links to both the formal publication through the relevant DOI and the license). See: https://creativecommons.org/licenses/by-nc-nd/4.0/.

\section{References}

1. Santarpia JL, Rivera DN, Herrera V, et al. Transmission potential of SARS-CoV-2 in viral shedding observed at the University of Nebraska Medical Center. medRxiv 2020. doi: 10.1101/2020.03.23.20039446.

2. Cowling BJ, Ali ST, Ng TWY, et al. Impact assessment of non-pharmaceutical interventions against coronavirus disease 2019 and influenza in Hong Kong: an observational study. Lancet Public Health 2020;5:e279-88.

3. Smith JD, MacDougall CC, Johnstone J, et al. Effectiveness of N95 respirators versus surgical masks in protecting health care workers from acute respiratory infection: a systematic review and meta-analysis. CMAJ 2016;188:567-74.

4. van der Sande M, Teunis P, Sabel R. Professional and home-made face masks reduce exposure to respiratory infections among the general population. PLoS One 2008;3:e2618.

5. Kai D, Goldstein GP, Morgunov A, et al. Universal Masking is Urgent in the COVID-19 Pandemic: SEIR and Agent Based Models, Empirical Validation, Policy Recommendations. arXiv 2020.

6. Mitze T, Kosfeld R, Rode J, et al. Face Masks considerably reduce COVID-19 cases in Germany: a synthetic control method approach. IZA Discussion Papers 2020.

7. Guidelines on COVID-19 Prevention and Control in Higher Education Institutes. Beijing: People' Medical Publishing House, 2020.

8. Ministry of Education of the People's Republic of China. The Programme for Prevention and Control of the Epidemic Disease of COVID-19 in Colleges and Universities. April 13, 2020. Available online: http://www. moe.gov.cn/jyb_xxgk/moe_1777/moe_1779/202010/ t20201021_495955.html (accessed December 1,2020).

9. WHO. Coronavirus disease (COVID-19) advice for the public: when and how to use masks. Available online: https://www.who.int/emergencies/diseases/novelcoronavirus-2019/advice-for-public/when-and-how-touse-masks (accessed March 17, 2020).

10. State Council, China. Guidelines for the selection and use of different types of masks for preventing new coronavirus infection in different populations 2020 (in Chinese).
Available online: http://www.gov.cn/xinwen/2020-02/05/ content_5474774.htm (accessed March 17, 2020).

11. Ministry of Health, Singapore. Updates on COVID-19 (coronavirus disease 2019) local situation. Available online: https://www.moh.gov.sg/covid-19 (accessed March 17, 2020).

12. CDC. Coronavirus Disease 2019 (COVID-19): steps to prevent illness. Available online: https://www.cdc.gov/ coronavirus/2019-ncov/about/prevention-treatment.html (accessed March 17, 2020).

13. Federal Ministry of Health, Germany. Daily updates on the coronavirus: is wearing a surgical mask, as protection against acute respiratory infections, useful for members of the general public? Available online: https://www. bundesgesundheitsministerium.de/en/press/2020/ coronavirus.html (accessed March 5, 2020).

14. Feng S, Shen C, Xia N, et al. Rational use of face masks in the COVID-19 pandemic. Lancet Respir Med 2020;8:434-6.

15. Wang J, Pan L, Tang S, et al. Mask use during COVID-19: a risk adjusted strategy. Environ Pollut 2020;266:115099.

16. Global Times. When wearing a mask invites discrimination against immigrants in the West. Available online: http://www.globaltimes.cn/content/1179484.shtml (accessed February 13, 2020).

17. WHO. Advice on the use of masks in the context of COVID-19: interim guidance. Available online: https:// www.who.int/publications-detail/advice-on-the-useof-masks-in-the-community-during-home-care-andinhealthcare-settings-in-the-context-of-the-novelcoronavirus-(2019-ncov)-outbreak (accessed April 15, 2020).

18. WHO. Shortage of personal protective equipment endangering health workers worldwide. Available online: https://www.who.int/news-room/detail/03-03-2020shortage-of-personal-protective-equipment-endangeringhealth-workers-worldwide (accessed March 17, 2020).

19. Tang CS, Wong CY. Factors influencing the wearing of facemasks to prevent the severe acute respiratory syndrome among adult Chinese in Hong Kong. Prev Med 2004;39:1187-93.

20. Wong CY, Tang CS. Practice of habitual and volitional health behaviors to prevent severe acute respiratory syndrome among Chinese adolescents in Hong Kong. J Adolesc Health 2005;36:193-200.

21. Li ZT, Yang SS, Zhang XX, et al. Complex relation among Health Belief Model components in TB prevention and care. Public Health 2015;129:907-15. 
22. Fadaei MH, Farokhzadian J, Miri S, et al. Promoting drug abuse preventive behaviors in adolescent students based on the health belief model. Int J Adolesc Med Health 2020;15:32.

23. Rajabalipour M, Sharifi H, Nakhaee N, et al. Application of social cognitive theory to prevent waterpipe use in male high-school students in Kerman, Iran. Int J Prev Med 2019;10:186.

24. Lowrey O, Ciampaglio K, Messerli JL, et al. Utilization of the transtheoretical model to determine the qualitative impact of a tribal FASD prevention program. Sage Open 2019. doi: $10.1177 / 2158244018822368$.

25. Blank MB, Hennessy M. A reasoned action approach to HIV prevention for persons with serious mental illness. Ann Am Acad Pol Soc Sci 2012;640:173-88.

26. Ajzen I, Madden TJ. Prediction of goal directed behavior: attitude, intention, and perceived behavioral control. J Exp Soc Psychol 1986;22:453-74.

27. Hansstein FV, Fabián E. Exploring motivations behind pollution-mask use in a sample of young adults in urban China. Global Health 2018;14:122.

28. Ajzen I. From intentions to actions: a theory of planned behavior. Heidelberg: Springer: Heidelberg, 1985:11-39.

29. He Y, Yang F, Mu D, et al. Examination of psychosocial predictors of Chinese hospital pharmacists' intention to provide clinical pharmacy services using the theory of planned behaviour: a cross-sectional questionnaire study. BMJ Open 2016;6:e012775.

30. Ajzen I. The theory of planned behavior. Organ Behav Hum Decis Process 1991;50:179-211.

31. Hadi Alizadeh S, Nooshin P, Mohammad V, et al. Health education intervention on HIV/AIDS prevention behaviors among health volunteers in healthcare centers: an applying the theory of planned behavior. J Soc Serv Res 2019;45:582-8.

32. Armitage CJ, Conner M. Efficacy of the theory of planned behaviour: a meta-analytic review. Br J Soc Psychol 2001;40:471-99.

33. Didarloo A, Sharafkhani N, Gharaaghaji R, et al. Application of theory of planned behavior to improve obesity-preventive lifestyle among students: a school-based interventional study. Int J Pediatr 2017;5:5975-6178.

34. Davey G, Mcclenahan C, Zhao X. Smoking intention among Chinese youth and implications for health interventions. Asia Pacific Journal of Counselling \& Psychotherapy 2014;5:71-86.

35. Şimşekoğlu Ö, Lajunen T. Social psychology of seat belt use: a comparison of theory of planned behavior and health belief model. Transportation Research Part F: Traffic Psychology and Behaviour 2008;11:181-91.

36. Tavafian SS, Aghamolaei T, Gregory D, et al. Prediction of seat belt use among Iranian automobile drivers: application of the theory of planned behavior and the health belief model. Traffic Inj Prev 2011;12:48-53.

37. Ali M, Haidar N, Ali MM, et al. Determinants of seat belt use among drivers in Sabzevar, Iran: a comparison of theory of planned behavior and health belief model. Traffic Inj Prev 2011;12:104-9.

38. Brijs K., Brijs T, Sann S, et al. Psychological determinants of motorcycle helmet use among young adults in Cambodia. Transportation Research 2014;26:273-90.

39. Ross LT, Ross TP, Farber S, et al. The theory of planned behavior and helmet use among college students. Am J Health Behav 2011;35:581-90.

40. Zhang J, Sha Z, Gu Y, et al. Predicting behavioral intentions related to cervical cancer screening using a three-level model for the TPB and SCT in Nanjing, China. Int J Environ Res Public Health 2019;16:3575.

41. Rezabeigi-Davarani E, Khanjani N, Falahi M, et al. Breast self-examination and its effective factors based on the theory of planned behavior among women in Kerman, Iran. Journal of Education and Community Health 2018;3:1-8.

42. Zong X, Li T. Distribution evolution and trend forecast of overseas students from One Belt And One Road countries. Higher Education Exploration 2020;4:91-9.

43. Petosa RL, Smith LH. Peer mentoring for health behavior change: a systematic review. Am J Health Educ 2014;45:351-7.

44. ABC news. COVID-19 in the quad: Colleges crack down on student parties as virus spreads across campuses. Available online: https://abcnews.go.com/US/covid-19quad-colleges-crack-student-parties-virus/story?id=724 99108\&cid=clicksource_4380645_3_heads_hero_live_ headlines_hed (accessed August 23, 2020).

45. Roncancio AM, Ward KK, Fernandez ME. Understanding cervical cancer screening intentions among Latinas using an expanded theory of planned behavior model. Behav Med 2013;39:66-72.

46. Karimy M, Zareban I, Araban M, et al. An extended theory of planned behavior (TPB) used to predict smoking behavior among a sample of Iranian medical students. Int J High Risk Behav Addict 2015;4:e24715.

47. Li Z . The investigate of the risk behavior of driving on the road in Chiang Mai. Kunming: Kunming University of Science and Technology, Kunming, 2018. 
48. Griethuijsen RALF, Michiel W, Helen H, et al. Global patterns in students' views of science and interest in science. Res Sci Educ 2015;45:581-603.

49. Jiangsu. A total of 32, 000 foreign students were enrolled in our province this year. December 28, 2016. Available online: http://www.jiangsu.gov.cn/art/2016/12/28/ art_33686_2312929.html (accessed August 18, 2020).

50. Raosoft. Raosoft sample size calculator. Available online: http://www.raosoft.com/samplesize.html (accessed August $18,2020)$.

51. Lessler JT, Kalsbeek WD. Missing error in surveys. Beijing: China Statistics Press, 1997:242.

52. Ministry of Education of the People's Republic of China. International students studying in China in 2018. April 12, 2019. Available online: http://www.moe.gov.cn/jyb_ xwfb/gzdt_gzdt/s5987/201904/t20190412_377692.html (accessed October 8, 2020).

53. Suh Y. The performance of maximum likelihood and weighted least square mean and variance adjusted estimators in testing differential item functioning with nonnormal trait distributions. Struct Equ Model A Multidiscip J 2015;22:568-80.

54. Byrne BM. Structural equation modeling with AMOS: basic concepts, applications, and programming. New York: Routledge, 2010.

55. Byrne BM. Structural equation modeling with LISREL, PRELIS, and SIMPLIS: basic concepts, applications, and programming. New York: Psychology Press, 2013.

56. Hu L, Bentler PM. Cutoff criteria for fit indexes in covariance structure analysis: conventional criteria versus new alternatives. Structural Equation Modeling 1999;6:1-55.

Cite this article as: Sun Y, Qin B, Hu Z, Li H, Li X, He Y, Huang H. Predicting mask-wearing behavior intention among international students during COVID-19 based on the theory of planned behavior. Ann Palliat Med 2021;10(4):3633-3647. doi: 10.21037/apm-20-2242
57. MacCallum RC, Browne MW, Sugawara HM. Power analysis and determination of sample size for covariance structure modeling. Psychol Methods 1996;1:130-49.

58. Miles J, Shevlin M. A time and a place for incremental fit indices. Personality \& Individual Differences 2007;42:869-74.

59. Bentler PM, Bonett DG. Significance tests and goodness of fit in the analysis of covariance structures. Psychol Bull 1980;88:588-606.

60. Fornell C, Larcker D. Evaluating structural equation models with unobservable variables and measurement error. Journal of Marketing Research 1981;18:39-50.

61. Gefen D, Straub D. A practical guide to factorial validity using PLS-graph: tutorial and annotated example. Communications of the Association for Information Systems 2005;16:91-109.

62. Xu Z, Shan J, Li J, et al. Extending the theory of planned behavior to predict public participation behavior in air pollution control: Beijing, China. Journal of Environmental Planning and Management 2020;63:669-88.

63. Cava MA, Fay KE, Beanlands HJ, et al. Risk perception and compliance with quarantine during the SARS outbreak. J Nurs Scholarsh 2005;37:343-7.

64. Tobol Y, Siniver E, Yaniv G. Dishonesty and mandatory mask wearing in the COVID-19 pandemic. Econ Lett 2020;197:109617.

65. Banaeian S, shayesteh A, Kazemian S, et al. Knowledge, attitude and practice about breast cancer screening and related factors among women referred to health care centers in Boroujen in 2005. Journal of Shahrekord University of Medical Sciences 2006;7:28-34. 